\title{
CULTIVO E BENEFICIAMENTO DE Manihot esculenta Crantz. PELOS AGRICULTORES FAMILIARES DA COMUNIDADE AÇAIZAL MONTE ALEGRE, PARÁ
}

\author{
Sandy Santos da Fonseca'; Roberta Rowsy Amorim de Castro². \\ 1Universidade Federal do Pará (UFPA), Abaetetuba, Pará, sandysandyze@gmail.com \\ 2UFPA, Abaetetuba, Pará, roberta_rowsy@hotmail.com
}

\begin{abstract}
RESUMO: O presente estudo objetivou compreender e descrever como se dão as práticas agrícolas e de beneficiamento empregadas no sistema de cultivo da mandioca (Manihot esculenta Crantz.) pelos agricultores da Comunidade Açaizal, município de Monte Alegre, estado do Pará. A investigação ocorreu durante 15 dias, por meio de formulário aplicado em 21 unidades produtivas e de acompanhamento in loco das etapas de colheita, processamento e venda da farinha de mandioca. O acesso às unidades se deu via motocicleta e caminhadas, esta última em trechos de difícil acesso. Os resultados indicaram que as práticas agrícolas adotadas pelos agricultores no sistema de cultivo de mandioca são provenientes de saberes adquiridos e repassados entre gerações, sendo a produção de farinha a principal fonte de obtenção de renda, além de fazer parte da dieta alimentar das famílias estudadas. Constatou-se que o sistema de corte e queima, adotado nas unidades familiares vem despertando preocupação nos agricultores acerca da perpetuação das práticas de cultivo e consequentemente de beneficiamento da mandioca para as próximas gerações em virtude da percepção destes do empobrecimento do solo.
\end{abstract}

PALAVRAS-CHAVE: Agricultura Familiar, Amazônia, Farinha de Mandioca, Sistema de Produção.

\section{CULTIVATION AND PROCESSING OF Manihot esculenta Crantz. BY FAMILY FARMERS OF THE AÇAIZAL COMMUNITY IN THE CITY OF MONTE ALEGRE, STATE OF PARÁ}

\begin{abstract}
The present study aimed to understand and describe how the agricultural and processing practices employed in the manioc (Manihot esculenta Crantz.) cultivation system are carried out by the farmers of the Açaizal community, in the city of Monte Alegre, in the state of Pará. The investigation took place during 15 days, through a form applied in 21 production units and follow-up at the site of the stages of harvesting, processing and sale of manioc flour. The access to the productive units happened by means of motorcycle and hiking, these latter in stretches of difficult access. The results indicated that the agricultural practices adopted by farmers in the manioc cultivation system is derived from knowledge acquired and passed on between generations, with flour being the main source of income, as well as being part of the diet of the families studied. It was observed in the family units that the system of cutting and burning of the vegetation has raised concern in the farmers
\end{abstract}


for the continuation of the practices of cultivation of manioc for the next generations because of your perception of the impoverishment of the soil.

KEYWORDS: Family Farming, Amazon, Manioc Flour, Production System.

\section{CULTIVO Y BENEFICIAMIENTO DE Manihot esculenta Crantz. POR LOS AGRICULTORES FAMILIARES DE LA COMUNIDAD AÇAIZAL MONTE ALEGRE, PARÁ}

RESUMEN: El presente estudio objetivó comprender y describir cómo se dan las prácticas agrícolas y de beneficiamiento empleadas en el sistema de cultivo de la mandioca (Manihot esculenta Crantz.) Por los agricultores de la Comunidad Açaizal, municipio de Monte Alegre, estado de Pará. La investigación ocurrió durante 15 días, por medio de formulario aplicado en 21 unidades productivas y de seguimiento in situ de las etapas de cosecha, procesamiento y venta de la harina de mandioca. El acceso a las unidades se dio vía motocicleta y caminatas, esta última en tramos de difícil acceso. Los resultados indicaron que las prácticas agrícolas adoptadas por los agricultores en el sistema de cultivo de mandioca proceden de saberes adquiridos y transferidos entre generaciones, siendo la producción de harina la principal fuente de obtención de renta, además de formar parte de la dieta alimentar de las familias estudiadas. Se constató que el sistema de corte y quema, adoptado en las unidades familiares, ha despertado preocupación en los agricultores acerca de la perpetuación de las prácticas de cultivo y consecuentemente de beneficiamiento de la mandioca para las próximas generaciones en virtud de la percepción de éstos del empobrecimiento del suelo.

PALABRAS CLAVE: Agricultura Familiar, Amazonia, Harina de Mandioca, Sistema de Producción.

\section{INTRODUÇÃO}

Segundo o Ministério do Meio Ambiente (2006) a mandioca é uma planta originária do Brasil ou de regiões limítrofes a este, sendo cultivada por todo - país, existindo grande variedade de raízes adaptadas as diferentes condições de clima e solo, além de uma multiplicidade de saberes local e pesquisas científicas sobre a mesma acumuladas ao longo dos anos, o que contribui para a elaboração de inúmeros produtos tradicionais e industriais que se destinam, na maioria das vezes, ao ramo alimentício.

A mandioca é uma espécie de planta com grande importância econômica e cultural, sendo amplamente empregada 
na dieta alimentar das populações rurais e urbanas especialmente da Amazônia sob a forma de seu produto principal, que é a farinha (LIMA et al., 2012).

Apesar da região amazônica compreender uma imensidão de áreas onde se praticam diversos tipos de agriculturas é no estado do Pará onde encontra-se um tipo peculiar de agricultura, expressa pelas populações locais para a produção de mandioca, cujos saberes, práticas e usos são mantidos culturalmente pela agricultura familiar de subsistência em pequenas propriedades rurais (MINISTÉRIO DO MEIO AMBIENTE, 2006).

Linhares e Santos (2014) ressaltam que muitas dessas propriedades rurais estão localizadas em comunidades onde a mandioca representa a base da dieta alimentar na forma de farinha, consumida juntamente com outras fontes de proteínas ou ainda na forma de produtos como beijus, tapioca (goma), tucupi e farinha de tapioca. Cardoso et al. (2001) complementam que a mandioca paraense é geradora de trabalho, renda e ajuda na fixação do homem no campo.
Assim, o objetivo deste trabalho foi compreender, analisar e descrever como se dão as práticas agrícolas e de beneficiamento empregadas no sistema de cultivo da mandioca (Manihot esculenta Crantz.) pelos agricultores da Comunidade Açaizal, localizada no município de Monte Alegre no estado do Pará.

\section{MATERIAL E MÉTODOS}

O trabalho foi realizado no município de Monte Alegre, situado na região do baixo Amazonas, estado do Pará (PEREIRA et al., 2013) sob as coordenadas geográficas $02^{\circ} 00^{\prime} 15^{\prime \prime} \mathrm{S}$ e $54^{\circ} 04^{\prime}$ 45"W (SEPOF, 2012). A escolha da área se deu em virtude da carência de estudos científicos que abordem o cultivo e processamento da mandioca, operados pela agricultura familiar no município, e especialmente, na Comunidade Açaizal, considerando a grande importância deste cultivo na alimentação, subsistência e geração de renda das famílias locais.

A Comunidade Açaizal pertence a zona rural de Monte Alegre, sendo necessário para chegada ao ponto inicial de sua entrada percorrer a Rodovia 
Estadual PA-423 por 30 km e em seguida adentrar a Rodovia Estadual PA-425, ambas não asfaltadas. $O$ trecho da PA425 em que os moradores se reconhecem como pertencentes a Comunidade Açaizal estende-se por cerca de 8 km.

Desta área, informações obtidas por meio de visitas à comunidade e conversas informais com a agente comunitária de saúde local levaram a constatação de um universo amostral de 33 unidades familiares, e deste total participaram da investigação 64\%, isto é, 21 famílias. A quantidade da amostra foi definida em função das dificuldades de transporte e distância entre as unidades produtivas, somadas as situações em que após duas tentativas não se encontrou os responsáveis pelas propriedades, por estarem na cidade, doentes ou viajando.

O levantamento das informações em campo ocorreu durante15 dias do mês de junho de 2015, onde foram realizadas visitas as famílias e aplicação de formulário semiestruturado. As informações foram colhidas junto aos agricultores em suas residências. $\bigcirc$ acesso às unidades familiares se deu via motocicleta e caminhadas em trechos de difícil acesso. A estadia e permanência na localidade foram viabilizadas pela hospedagem em uma unidade familiar da comunidade.

No formulário versaram questões sobre o itinerário técnico adotado para a referida cultura, tais como tratos culturais, plantio, manejo de pragas e doenças, mão de obra utilizada, beneficiamento e comercialização da mandioca. Para complementação ao estudo, durante a efetivação desta etapa surgiu a oportunidade de acompanhar os agricultores atuando diretamente na colheita, processamento e venda da mandioca. Para tanto foi utilizada da técnica de observação, sem participação nas atividades, conforme Beaud e Weber (2007).

Os métodos de pesquisa utilizados oportunizaram conhecer o sistema de produção, compreender o processo de cultivo das raízes de mandioca bem como a lógica de beneficiamento da farinha, isso porque a pesquisa se deu no âmbito dos princípios metodológicos da Abordagem Sistêmica e da Teoria de Sistemas Agrários (MAZOYER; ROUDART, 2010). Nesse sentido, ressalta-se que este trabalho é 
parte da Análise Diagnóstico do Sistema Agrário da Comunidade Açaizal, onde uma das etapas consiste no diagnóstico e tipologia dos sistemas de produção e dada a relevância e destaque do cultivo e beneficiamento de mandioca na comunidade estudada, este sistema foi escolhido como tema desse artigo.

Os dados coletados em campo foram organizados no software Microsoft Excel 2010, sendo que as imagens e anotações também coletadas em campo serviram como complemento ao estudo.

\section{RESULTADOS E DISCUSSÃO}

CULTIVO E PRODUÇÃO DE MANDIOCA NA COMUNIDADE AÇAIZAL

A Comunidade Açaizal é formada por famílias de agricultores que residem em três sub-regiões denominadas: Açaizal faixa (PA-425), Ramal Paxiúba e Ramal Igarapé do Meio, sendo que 95,25\% dos entrevistados são pessoas nascidas no município de Monte Alegre, que ocupam, há pelo menos 40 anos, lotes cujos tamanhos variam de 0,25 a 60 hectares. Constatou-se que a tomada de decisões relacionada a gestão das unidades produtivas é compartilhada pelo casal e os filhos participam das atividades diárias como complemento a mão de obra.

As principais atividades desenvolvidas nas unidades produtivas dos agricultores na Comunidade Açaizal são os subsistemas de cultivos anuais como milho (Zea mays L.), feijão branco (Vigna unguiculata (L.) Walp.), arroz (Oriza sativa) e cultivos de ciclo curto como a mandioca, além do sistema de criação de animais de grande porte como bovinos e equinos, de médio porte como suínos e de pequeno porte como aves.

Os cultivos anuais e de ciclo curto destinam-se ao consumo das famílias e dos animais de médio e pequeno porte, e estes, por sua vez, destinam-se a complementação da dieta alimentar dos agricultores. Os animais de grande porte destinam-se somente a venda e os cultivos de ciclo curto são direcionados para a venda e consumo na forma de farinha de mandioca (VELTHEM; KATZ, 2012).

O cultivo de mandioca tem importância social, alimentar e econômica para as famílias na Comunidade Açaizal, isso porque garante a permanência das mesmas no campo, já que se configura 
como um meio de subsistência, por ser uma fonte nutricional e geradora de renda, corroborando com Silva et al. (2014) que considera a mandioca como opção de cultivo para as populações tradicionais da Amazônia pois melhora a qualidade de vida das mesmas comunidades, reduz o fluxo migratório de pessoas do campo para as cidades, além de contribuir para a segurança alimentar.

Constatou-se que o manejo das roças de mandioca é estabelecido pelos agricultores em monocultivo, rotação e consórcios, sendo este último o mais frequente e estabelecido junto com culturas anuais como milho e feijão branco em áreas pequenas cujo tamanho não chega a um hectare. Castro e Oliveira (2015) destacaram que o tamanho da área cultivada é associado a capacidade produtiva da família, que desde o plantio da mandioca até a produção da farinha utiliza-se de todos os seus membros como mão de obra operante, assim como ocorre na comunidade Açaizal.

O preparo do solo é feito no sistema de corte e queima ou itinerante, conforme Silva et al. (2009), entre os meses de novembro e dezembro, em áreas de capoeiras grossas com mais de trinta anos ou em áreas de capoeira fina deixadas em pousio de roçados anteriores, sendo esta última a mais comum nas unidades produtivas da comunidade estudada.

O plantio das manivas geralmente ocorre a partir do mês de janeiro por causa do início das chuvas na região. Identificou-se o uso e emprego de ferramentas de fácil manuseio como enxadas e enxadecos para a abertura de covas rasas onde as manivas são plantadas. O espaçamento predominante nas roças dos agricultores é o de 1,00 metro $\times 1,00$ metro entre covas. O material de propagação das manivas é obtido nas propriedades dos agricultores, de vizinhos ou em outras comunidades, onde as manivas são escolhidas com base na aparência fitossanitária e as ramas são cortadas manualmente com facão no formato bisel (corte inclinado), em tamanhos aproximados de 20 centímetros de comprimento.

Na Comunidade Açaizal os agricultores trabalham com o manejo de pelo menos duas variedades de tubérculos para a produção de farinha, a primeira é nomeada popularmente de 
Amareli e a segunda é chamada de Pirara, ambas apresentam como principal diferença a coloração da carne (mandioca). Segundo os mesmos, a Amareli confere a farinha o aspecto amarelado e a Pirara o aspecto creme, por isso eles costumam misturar as duas raízes durante o processo de beneficiamento para obter uma coloração média do produto.

Entre os principais tratos culturais após o plantio estão a capina e o roço com foices. As capinas ocorrem em dois períodos, sendo o primeiro cerca de trinta dias após o plantio para diminuir a competição por nutrientes com plantas daninhas e o segundo noventa dias após o plantio, e posteriormente, até a colheita é feito o controle de plantas daninhas com roço manual.

A enxada e a foice são as principais ferramentas de trabalho empregadas na condução do cultivo de mandioca, pelos mesmos motivos identificados por Neves et al. (2013), que são o baixo custo de obtenção no mercado, tradição histórica e eficiência de uso em pequenas áreas.

Com relação as pragas e doenças, os agricultores alegaram leves interferências, ocasionadas por animais silvestres como tatus (Dasypus marsupiales), que reviram o solo ao redor das raízes de mandioca e/ou provocam injúrias que levam ao seu apodrecimento ou deixam suscetíveis ao ataque de insetos e outros animais do meio.

A colheita das raízes é iniciada a partir ou após doze meses a contar da realização do plantio, conforme a necessidade das famílias para a produção de farinha artesanal. Esta tem dupla finalidade na comunidade: o consumo alimentar e a comercialização do excedente como meio para obtenção de renda.

A exploração das roças de mandioca perdura por um período de dois a três anos após o início da colheita (que ocorre, geralmente, um ano após o plantio, como já descrito), isso porque os agricultores retiram apenas o suficiente para manter o estoque alimentar e a comercialização. Constatou-se que em 12 unidades, cujas áreas são menores que 20 hectares, é produzido em torno de um saco de sessenta quilos por mês, e em nove unidades, com áreas superiores a este 
tamanho, chega-se a produzir cerca de cinco sacos por mês.

Esse cenário se assemelha ao estudo de Lopes (2006) onde a colheita da mandioca é realizada manualmente após um ano de plantio, e em alguns casos até antecipando essa etapa devido a necessidade do grupo familiar, sendo que após a colheita normalmente as áreas cultivadas são deixadas em pousio, com intervalos de 3 a 5 anos nas capoeiras finas e de 10 a 30 anos nas capoeiras grossas, ou são transformadas em áreas de pastagem. Na comunidade Açaizal, após a colheita completa das raízes de mandioca os agricultores, dependendo dos meios de produção que dispõem (terra, mão de obra, capital), deixam a área cultivada em pousio para regeneração da vegetação, ou realizam novos plantios anuais, ou destinam as áreas para formação de pastagens.

Na Figura 1 o agricultor realiza a colheita de mandioca com idade de 14 meses, com o auxílio de facão e de foice. Durante a colheita é comum a presença de esposas e filhos (as) nos roçados, onde as mulheres ficam responsáveis pela decota, que é como eles chamam o corte da raiz separando-a do resto da planta, e os filhos mais velhos ajudam o pai na retirada das raízes do solo ou carregando estas para formação de um monte com raízes para facilitar o processo de transporte.

Figura 1. Colheita de mandioca aos 14 meses em unidade familiar localizada no Ramal Igarapé do Meio a 4 km da faixa PA-425, Comunidade Açaizal, Monte Alegre, PA.

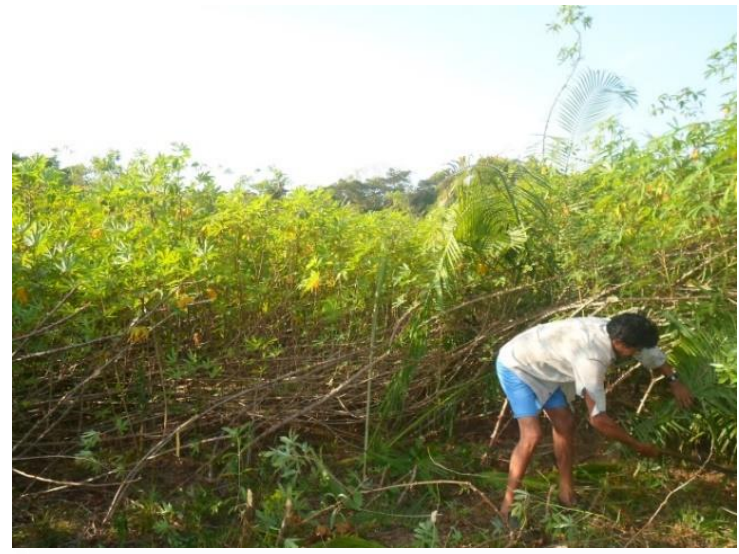

Fonte: Elaborado pelo Autor.

De acordo com os agricultores a melhor hora do dia para a colheita da mandioca é o período da manhã, antes do sol esquentar, porque o solo ainda está úmido da relva, o que facilita a retirada das raízes, o clima ameno reduz o desgaste físico e o término da colheita 
pela manhã não atrapalha o cronograma de atividades de um dia de farinhada.

A Figura 2 apresenta, em síntese, as etapas de produção de mandioca nas unidades familiares da comunidade em estudo, com as principais ocorrências (atividades) realizadas em cada fase, desde o preparo da área até a colheita, visto que o processamento das raízes para elaboração de subprodutos envolve outras ações que serão descritas posteriormente.

Figura 2. Etapas de produção de mandioca nas unidades familiares da Comunidade Açaizal, Monte Alegre, PA.

ETAPAS DE PRODUÇ̃̃O DE MANDIOCA NAS UNIDADES FAMILIARES DE AÇAIZAL

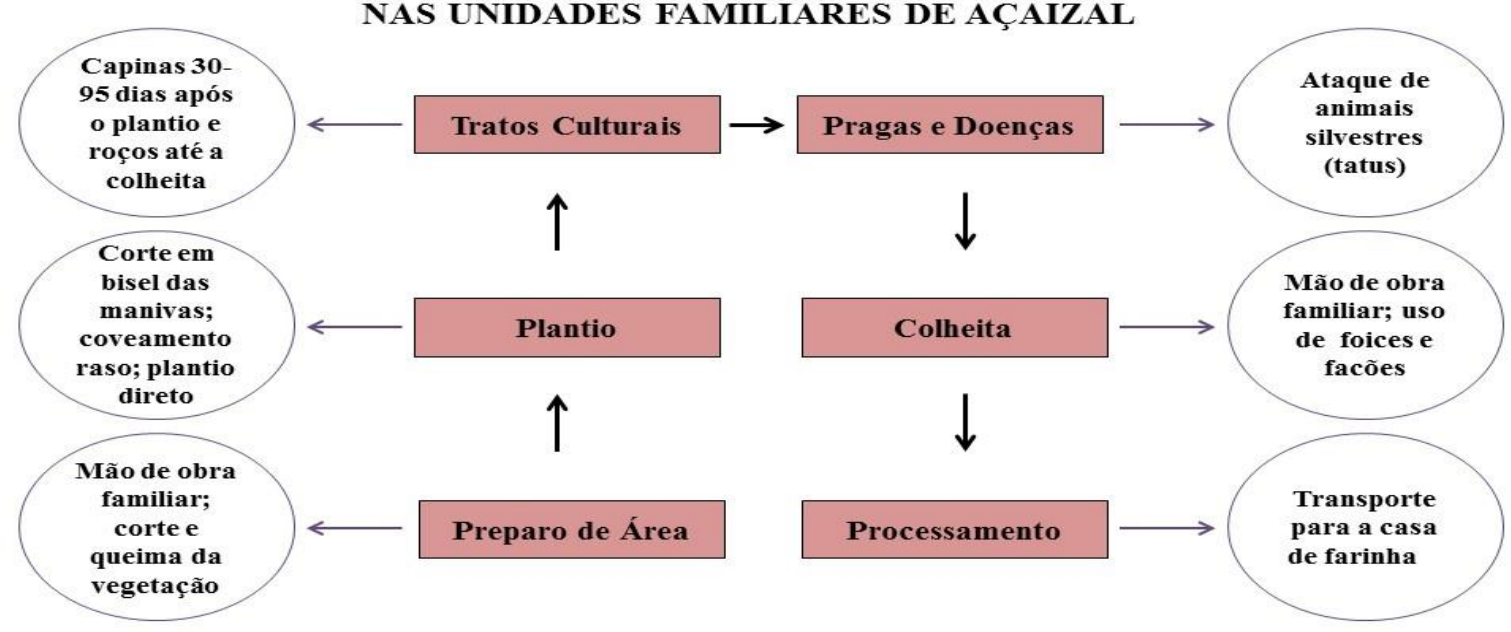

Fonte: Elaborado pelo Autor.

BENEFICIAMENTO DA MANDIOCA E A TRANSFORMAÇÃO EM FARINHA E OUTROS SUBPRODUTOS

O transporte dos tubérculos para as casas de farinhas é feito via carroças de boi, carrinho de mão ou nas costas. Cardoso et al. (2001) discorre que é na casa de farinha tradicional onde ocorrem todas as fases de processamento artesanal da mandioca, utilizando, para isso, instrumentos rústicos. Entre os elementos constituintes das casas de farinha identificadas nas unidades familiares da Comunidade Açaizal estão forno, prensa de madeira, peneiras, banco com motor e gareiras. Estas últimas são 
recipientes confeccionados em madeira semelhantes a gamelas ou cochos. Na Figura 3 as setas vermelhas identificam as gareiras na casa de farinha.

Após a colheita ocorre o processamento ou beneficiamento da mandioca, onde as raízes são transportadas para a casa de farinha, e na sequência as cascas são retiradas (raspagem), as raízes são lavadas e colocadas para a ralação, a massa fresca é prensada, peneirada, escaldada, peneirada novamente e torrada (VELTHEM; KATZ, 2012), conforme esquema da Figura 4.

Figura 3. Gareiras utilizadas para produção de farinha de mandioca (setas vermelhas) em unidade familiar na Comunidade Açaizal, Monte Alegre, PA.

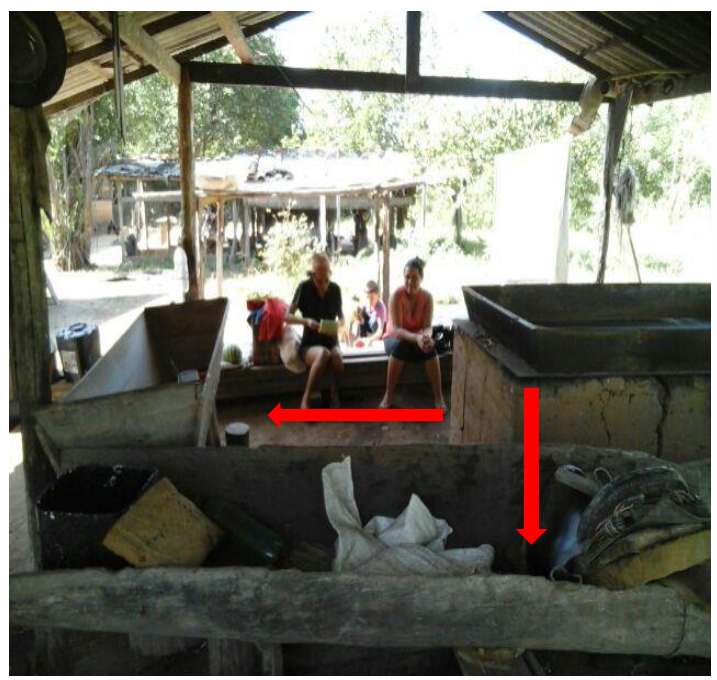

Fonte: Elaborado pelo Autor.
Figura 4. Etapas de processamento da mandioca na Comunidade Açaizal, Monte Alegre, PA.

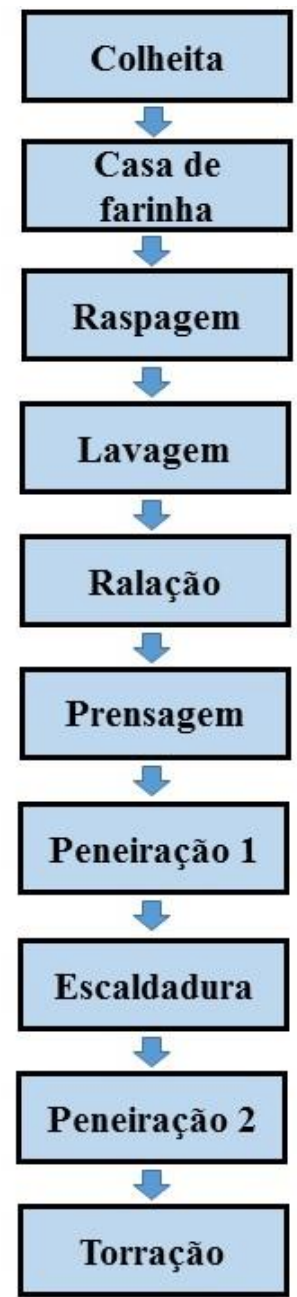

Fonte: Elaborado pelo Autor.

Devido às várias etapas que se seguem para a elaboração da farinha, esta é uma atividade que demanda bastante mão de obra, por isso todos os membros da família costumam ajudar. Segundo Lopes (2006), e, Castro e Oliveira (2015) é durante a vivência de todo o processo que envolve a produção da farinha que os 
saberes e conhecimentos são repassados e mantidos ao longo das gerações entre pais e filhos.

Na casa de farinha, as raízes são descascadas ou raspadas com o auxílio de facas e rapadores de ferro, estes últimos confeccionados pelos próprios agricultores. As cascas retiradas durante o processo são lançadas próximo à casa de farinha, servindo de alimento para os animais do terreiro e para nutrir o solo após decomposição.

As raízes descascadas são imersas em água para retirada de resíduos (Figura 5) e, segundo os agricultores, para evitar arroxeamento. Nesse processo, normalmente são usados grandes recipientes como caixas d'água, tanques de concreto, camburões de plástico ou, em alguns casos, a lavagem é feita em água corrente de igarapés.

Após a limpeza, as raízes são colocadas no que é chamado pelos agricultores de banco de cevar, adaptado com motor a base de gasolina. Tradicionalmente os agricultores acrescentam raízes pubas ou pubadas, que conforme Castro e Oliveira (2015), junto as raízes frescas para a ralação.
Figura 5. Mandiocas imersas em água após a retirada das cascas na Comunidade Açaizal, Monte Alegre, PA.

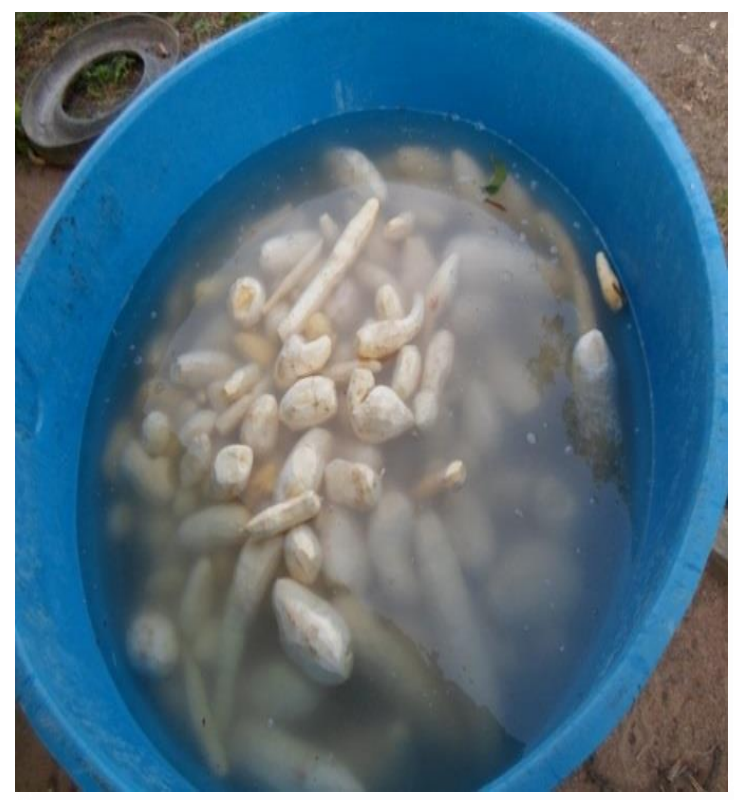

Fonte: Elaborado pelo Autor.

Para essa atividade eles colhem uma pequena quantidade de mandioca (cerca de $10 \%$ do peso total da colheita) cinco dias antes da farinhada e deixam mergulhadas em água para obter a massa puba. Curiosamente, eles selecionam a raiz do tipo Amareli para tirar a massa puba, segundo os mesmos, porque a coloração fica mais intensa durante o processo (Figura 6), funcionando como um corante natural e saudável.

Na prensagem a massa fresca é colocada dentro de sacos de fibras que são sobrepostos em uma prensa de 
madeira para que o tucupi ${ }^{1}$ escorra, essa etapa leva algumas horas até que a massa esteja seca.

Antes de a massa ir para a prensagem algumas famílias retiram, esporadicamente, pequenas quantidades de tapioca (goma) e tucupi para o consumo. Tal atividade é geralmente efetuada pelo sexo feminino, o método consiste nas ações que Vizolli et al. (2012) denominaram de lavagem da massa e coar a massa.

De maneira semelhante aos procedimentos citados por Vizolli et al. (2012) os agricultores da Comunidade Açaizal separam pequenas porções da massa fresca ralada em vasilhames, onde adicionam água e misturam com as mãos até a completa homogeneização e em seguida, em outro reservatório, despejam a mistura em pequenos sacos de pano, semelhantes a coadores. Após o acúmulo de massa no coador, este é contorcido até os últimos respingos de líquido serem

\footnotetext{
1 O tucupi é um líquido venenoso contido nas partes aéreas e principalmente nas raízes da mandioca, onde dependendo da variedade, idade e de fatores como solo, temperatura e umidade, pode ocasionar morte de animais e do ser humano, devido a concentração de ácido cianídrico (CARDOSO, 2005). Contudo, no estado
}

despejados e a massa em seu interior é devolvida a massa fresca total ralada.

Figura 6. Agricultor realizando a ceva ou ralação da mandioca Pirara (raiz clara) juntamente com a massa puba de raiz Amareli (amarelada e mole) na Comunidade Açaizal, Monte Alegre, PA.

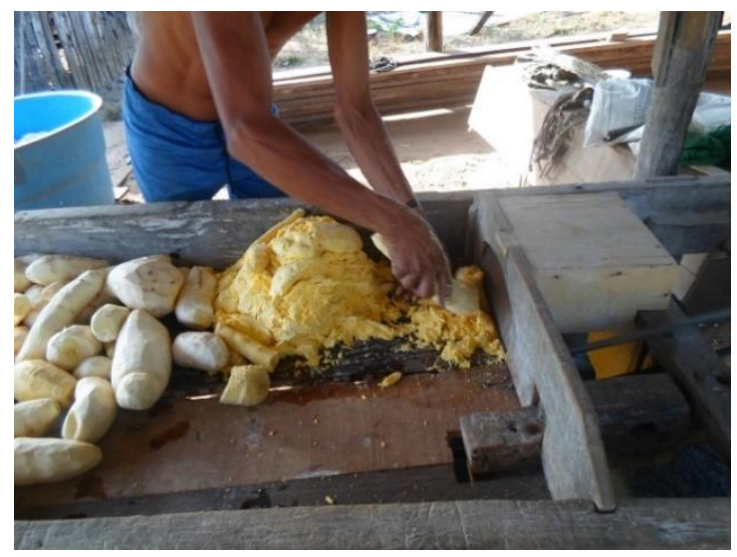

Fonte: Elaborado pelo Autor.

O processo se repete até que toda a mistura (massa fresca + água) passe pelo coador. O líquido restante é colocado em repouso por algumas horas para decantação, processo este que consiste na separação da parte sólida e da líquida em misturas heterogêneas, do tipo sólido e líquido. Após a decantação retira-se o

do Pará, este produto passa por um processamento, que é feito pelas próprias famílias produtoras, para perda do veneno, e o mesmo passa a ser utilizado como tempero e complemento alimentar em diversos pratos típicos. 
líquido, denominado tucupi, que consta na parte superior para fervura no fogo ou para fermentação a sol pleno.

Na parte inferior do recipiente resta a tapioca, goma ou polvilho, ainda com o que os agricultores chamam de "borra". A presença da "borra" deixa a tapioca amarelada, por isso costuma-se adicionar água limpa e misturá-la até a dissolução da tapioca. Após decantação a água com a "borra" pode ser despejada, este procedimento é repetido por várias vezes até que a tapioca esteja com a coloração branca.

Quando a massa é prensada, após os processos de produção de goma de tapioca e tucupi acima descritos, realizados em pequena escala pelas famílias estudadas, a mesma é peneirada para a retirada de partes que não foram totalmente raladas, deixando-a solta para a próxima etapa que é a escaldadura no forno.

A respeito da peneiração, a crueira (pedaços de mandioca) retirada pode ser utilizada na alimentação dos animais da propriedade, o que evidencia a relação solidária que pode existir entre os subsistemas de uma propriedade rural familiar.

Do mesmo modo ocorre com a lenha que alimenta o forno para as próximas etapas do beneficiamento, que incluem a escaldadura e a torração. A mesma é proveniente dos roçados, sendo raramente retirada das áreas de mata e capoeiras grossas. Lopes (2006) ressalta que a lenha é o principal combustível e fonte de energia calorífica usada nas atividades cotidianas dos agricultores, característica essa perpetuada por diversas gerações na comunidade estudada.

A escaldadura da massa é um processo demorado, realizado no forno pré-aquecido e mantido com pouca lenha, onde as ferramentas para manuseio da massa fresca podem ser pequenas espátulas, rodos e remos de madeira. Cuidadosamente os agricultores escaldam a farinha e em seguida realizam a segunda peneiração, desta vez para a retirada de "bagos", que são pedaços de massa escaldada que deixam a farinha grossa.

A torração é a etapa final do beneficiamento da farinha, logo o tempo 
discorrido é maior que na escaldadura, e a atenção dos agricultores é redobrada para acertar o ponto de crocância ideal. As ferramentas utilizadas podem ser rodos ou remos. Na Figura 7 o agricultor utiliza a ferramenta rodo.

Figura 7. Torração da farinha de mandioca na Comunidade Açaizal, Monte Alegre, PA.

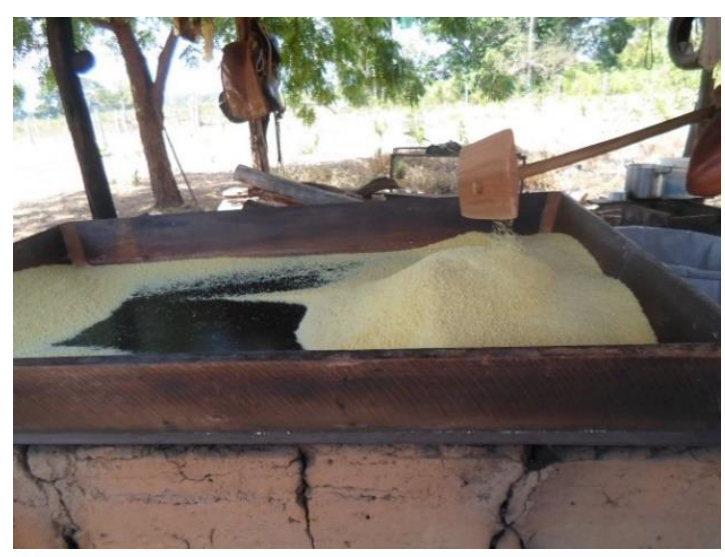

Fonte: Elaborado pelo Autor.

A respeito das etapas de trabalho nas casas de farinha da Comunidade Açaizal as fases que exigem mais força física são aquelas que envolvem o uso do forno e da prensa, sendo assumidas pelos homens, e as que necessitam de menor força como a raspagem das cascas, tiragem de tapioca, tucupi e peneiração são atribuídas as mulheres, o que não significa uma regra, pois dependendo da mão de obra disponível, homens e mulheres podem assumir qualquer etapa desse processo na casa de farinha.

Após a finalização do processo de torração, a farinha torrada é acondicionada em sacos de fibra (Figura 8), onde os agricultores costumam pesar sessenta quilos de farinha em cada saco para facilitar o manuseio e a venda. Geralmente, a comercialização é realizada junto aos atravessadores na feira do município de Monte Alegre, e estes por sua vez revendem a farinha no comércio local e/ou para outros municípios.

Figura 8. Farinha de mandioca torrada e ensacada, Comunidade Açaizal, Monte Alegre, PA.

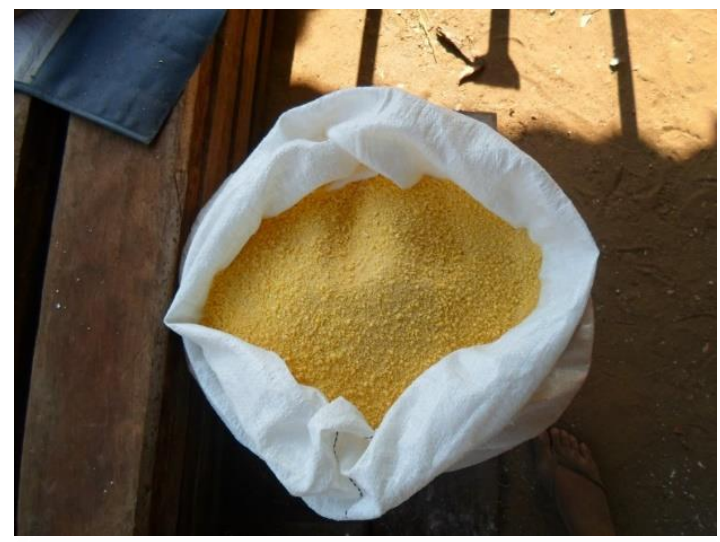

Fonte: Elaborado pelo Autor.

A principal via de escoamento da produção da farinha para a cidade ocorre por meio de transporte de linha do tipo caminhão comunitário, disponibilizado 
aos agricultores em dias específicos da semana, sendo que as transações comerciais ocorrem em espaço público, no centro da cidade, chamado de feira livre.

A farinha de mandioca é o produto final resultante desta interação entre os agricultores e o meio, sendo responsável pelas principais entradas e saídas de recursos financeiros. Na feira os preços variam conforme a época do ano e a qualidade da farinha, sendo levados em consideração, para a definição dos valores de comercialização, principalmente a aparência, sabor, granulometria e a crocância do produto. No ano de 2015, por exemplo, a farinha foi vendida ao preço médio de $\mathrm{R} \$ 100,00$ a saca de sessenta quilos.

Apesar de a mandioca ser a principal fonte de subsistência das famílias na Comunidade Açaizal, os investimentos na atividade são baixos por parte dos agricultores e do poder público, o que pode ser confirmado ao verificar que mais da metade das famílias produzem farinha em instalações de vizinhos ou parentes por não possuírem casa de farinha própria. Assim, a "troca de dias" entre famílias é uma prática corriqueira na Comunidade, que consiste em trocar mão de obra durante uma farinhada e outra, onde a reunião de famílias para a produção de farinha contribui não só para a complementação da força de trabalho, mas, principalmente, para o fortalecimento dos laços de amizade, familiaridade e reciprocidade.

Duarte et al. (2015) refletem que o modo como os agricultores atuam diretamente na natureza lhes confere uma identidade própria, onde sua realização como indivíduo está sujeita as relações que conseguem estabelecer com o meio, tais como a natureza, as pessoas ao seu redor (parentes e vizinhos) e até mesmo com o ambiente externo à comunidade, como a cidade, estando em constante aperfeiçoamento dos saberes, o que torna complexa a compreensão dos ambientes e ecossistemas em que vive.

As dificuldades de compreensão e consequentemente intervenções desastrosas na promoção do desenvolvimento rural nesses ambientes e ecossistemas são originadas, conforme Velthem e Katz (2012), de uma visão estreita da realidade baseada meramente 
no repasse de conhecimentos técnicos prejudicando a construção coletiva de conhecimentos entre técnica científica e saberes tradicionais.

Na Comunidade Açaizal as famílias agricultoras e produtoras de mandioca e farinha possuem características que se assemelham as descritas por Duarte et al. (2015), pois estão em constante processo de aprendizado, transmissão e perpetuação de saberes, sendo muitas de suas práticas mantidas conforme indicações que lhes foram ensinadas, em processos que à primeira vista podem parecer rústicos, mas que ao longo das gerações têm conseguido manter nutricional e economicamente as mesmas, apoiadas também em uma rede de relações sociais e comerciais que tem garantido a sustentabilidade local e transmissão desses conhecimentos.

Além disso, a interação dos agricultores com o meio proporciona o melhor uso do espaço na unidade familiar e gestão dos recursos naturais, o que foi verificado pela adoção de consórcios e rotações com outros cultivos, emprego de estratégias para driblar a deficiência de mão de obra constatada pela ocorrência de troca de dias entre os agricultores durante as farinhadas, bem como ações para prolongar a exploração agrícola e fertilidade do solo nas pequenas propriedades por meio de pousios e da decomposição dos restos culturais dos cultivos.

Contudo, existe certa preocupação dos agricultores locais com relação a sustentabilidade, a longo prazo, da atividade agrícola de produção de mandioca para as próximas gerações. Os mesmos demonstram não somente vontade que a atividade seja mantida na localidade, mas também anseiam por melhorias nas etapas de produção e beneficiamento da mandioca, visto que o reduzido número de casas de farinha influencia a implantação de melhorias nas instalações, bem como maior investimento na elaboração de subprodutos (beijus, farinha de tapioca, etc.) que poderiam ser comercializados na feira municipal.

Ademais, na percepção dos mesmos está ocorrendo o empobrecimento do solo, o que desperta preocupação quanto a continuidade das práticas agrícolas adotadas atualmente, isso porque o solo 
é a base de produção para o desenvolvimento das raízes de mandioca, apesar de ser considerada uma cultura rústica e pouco exigente em nutrientes.

\section{CONCLUSÃO}

Por meio do estudo verificou-se que o cultivo de mandioca na Comunidade Açaizal é de grande importância para as famílias, servindo como fonte de renda e complemento alimentar, o que garante suas subsistências.

A dinâmica de produção envolve desde os itinerários técnicos para implantação, condução, colheita e beneficiamento da mandioca, cujas práticas são realizadas no âmbito das famílias, sendo estas detentoras da principal força de gestão e execução das atividades, o que garante a reprodutibilidade das mesmas e a constante interação entre seus componentes por meio da entrada insumos e ferramentas e saída de produtos como a farinha de mandioca, que ao ser comercializada retorna ao sistema como fonte de renda que supre as principais demandas da família e do subsistema de cultivo.

Os saberes e conhecimentos arraigados ao sistema de cultivo de mandioca são acumulados e repassados ao longo das gerações, assim como a reciprocidade entre os agricultores que praticam a troca de dias nas farinhadas, compartilhando experiências, estabelecendo laços de amizade e mantendo a identidade cultural da localidade.

Ressalta-se, contudo a necessidade de maior investimento financeiro por parte do poder público na Comunidade, o que oportunizaria melhores condições para cultivo e escoamento da produção e, consequentemente maior retorno econômico às famílias, a partir de novas oportunidades de comercialização locais.

\section{REFERÊNCIAS}

BEAUD, S.; WEBER, F. Guia para a pesquisa de campo: produzir e analisar dados etnográficos. Petrópolis: Editora Vozes, 2007.

CARDOSO, E. Uso de manipueira como biofertilizante no cultivo do milho: avaliação do efeito no solo, nas águas subterrâneas e na produtividade do milho, Criciúma, 2005. 67 f. Dissertação 
(Mestrado em Ciências Ambientais). Universidade do Extremo Sul Catarinense, Criciúma, 2005.

CARDOSO, E. R.; MÜLLER, A. A.; SANTOS, A. I. M.; HOMMA, A. K. O.; ALVES, R. N. B. Processamento e comercialização de produtos derivados da mandioca no nordeste paraense. Belém: EMBRAPA, 2001, 29p. (Documento, 102)

CASTRO, R. R. A.; OlIVEIRA, M. C. C. Cultivo e beneficiamento de mandioca (Manihot esculenta (rantz.) em comunidades tradicionais da Reserva Extrativista Rio Xingu, Terra do Meio, Pará, 2015. In: CONGRESSO BRASILEIRO DE AGROECOLOGIA, 9. Revista Cadernos de Agroecologia, v.10, n³, 2015.

DUARTE, G. S. D.; GONÇALVES, K. G.; PASA, M. C. Agricultura e mão de obra familiar em uma comunidade da Baixada Cuiabana, MT, Brasil. Revista Biodiversidade, v.14, p.84-97, 2015.

LIMA, D.; STEWARD, A.; RICHERS, B. T. Trocas, experimentações e preferências: um estudo sobre a dinâmica da diversidade da mandioca no médio Solimões, Amazonas. Boletim do Museu Paraense Emílio Goeldi. Revista Ciências Humanas, v. 7, n. 2, p.371-396, 2012.

LINHARES, A. S.; SANTOS, C. V. "A casa de farinha é a minha morada": transformações e permanências na produção de farinha em uma comunidade rural na região do Baixo Tocantins-PA. Revista Agricultura Familiar, n.10, p.53-66, Belém, 2014.

LOPES, B. M. Uso da capoeira na extração de lenha em três comunidades locais no pólo Rio Capim do PROAMBIENTE-PA,
Belém, 2006. 99 f. Dissertação (Mestrado em Agriculturas Familiares e Desenvolvimento Sustentável). Universidade Federal do Pará, Belém, 2006.

MAZOYER, R.; ROUDART, L. História das agriculturas no mundo: do neolítico à crise contemporânea (Tradução de FALLUH, C.F.; FERREIRA, B.). São Paulo: Editora UNESP. Brasília, DF: NEAD, 2010. 568p.

MINISTÉRIO DO MEIO AMBIENTE - MMA. Agrobiodiversidade e diversidade cultural. Brasília, 2006. 82 p. (Série Biodiversidade, 20)

NEVES, S. L. S.; GERASEEV, L. C:; AUGUSTO, H. A. Dos saberes tradicionais à agroecologia: um estudo de caso das práticas agrícolas da comunidade vazanteira da Ilha do Jenipapo, Itacarambi-MG. Revista Brasileira de Agroecologia, v. 8 n. 2, p.44-61, 2013.

PEREIRA, E; RUBIO, T. M; BARBOSA, C. A. $P$. Documentação digital da arte rupestre: apresentação e avaliação do método em dois sítios de Monte Alegre, Amazônia, Brasil. Revista Ciências Humanas, v. 8, n. 3, p. 585-603, 2013.

Secretaria de Estado de Planejamento, Orçamento e Finanças - SEPOF. Estatística Municipal, Monte Alegre, Pará. Disponível em: <http://seicom.pa.gov.br/kitmineraca o/estatistica-municipal/regiao-do-baixo amazonas/MonteAlegre.pdf >. Acesso em: 12 jul. 2017.

SILVA, F. L.; SILVA, J. R.; SILVA, L. R. P. Efeito do desmatamento e do programa de transferência de renda Bolsa Família na produção da mandioca (Manihot Esculenta Crantz) no Estado do 
Pará. Observatorio de la Economía Latinoamericana

(on-line), Málaga, 2014. Disponível em:< http://www.eumed.net/cursecon/ecolat/b r/14/produzao-mandioca.html>. Acesso em: 12 jul. 2017.

SILVA, M. M.; LOVATO, P. E.; VIEIRA, I. C. O Sistema de Produção de Corte e Queima desenvolvido pelos agricultores familiares na Região da TransamazônicaPará. Revista Brasileira de Agroecologia, v. 4, p.4401-4404, 2009.

VELTHEM, L. H. V; KATZ, E. A "farinha especial": fabricação e percepção de um produto da agricultura familiar no vale do rio Juruá, Acre. Boletim do Museu Paraense Emílio Goeldi. Revista Ciências Humanas, v. 7, n. 2, p.435-456, 2012.

VIZOLLI, I.; SANTOS, R. M. G.; MACHADO, R. F. Saberes Quilombolas: um estudo no processo de produção da farinha de mandioca. Revista Bolema, v.26, p.589608, 2012. 